\title{
Biotechnology and the Environment
}

\author{
Sandra S. Batie \\ Elton R. Smith Professor in \\ Food and Agricultural Policy, \\ Agricultural Economics \\ Michigan State University
}

$\mathrm{T}$ he nature of the relationship between biotechnology products and the environment is highly controversial. While agricultural biotechnology has great promise for the obtaining of both more food and a higher quality environment, there is currently much anxiety as to whether this promise is an illusion.

There are those who argue that there are no new nor unique hazards that accompany biotechnology, that it is a natural extension of past plant and animal breeding successes. Any risks that might occur are similar to those associated with those risks accompanying plants and animals from more traditional agricultural breeding. Thus, there are neither different nor greater safety concerns presented by biotechnology than we have dealt with in the past (GAO 1993; Tiedje et al. 1989).

Many vehemently disagree and assert that biotechnology is a radical new method posing unknown and unpredictable risks. Therefore, there must be extraordinary caution in the development and use of biotechnology products (GAO 1993; Rissler and Mellon 1993). There is much to examine within this topic, including issues of food safety. ${ }^{1}$ However, this brief discussion explores (without attempt at validation) only the arguments that frame the debate of the environmental impacts of agricultural biotechnology.

\section{THE POTENTIAL OF AGRICULTURAL BIOTECHNOLOGY}

Hindmarsh (1991) asserts that the proponents of biotechnology base their claims of environmental compatibility on four major promises. These are: 1. that herbicide-tolerant or herbicide-resistant crop research will enable hazardous herbicides to be replaced with environmentally friendly ones; 2 . that genetic engineering will enable the reduction of agrichemical use to counteract the growing resistance of insects and weeds by offering more precision than broad-spectrum insecticides; 3 . that the development of nitrogen-fixing plants will reduce the use of chemical fertilizers; and 4. that there is a low risk

${ }^{1}$ The food safety issues include an increase in levels of naturally occurring toxins or of allergens in the food supply; an adverse change in the composition, absorption or metabolism of important nutrients; or a reduction in the effectiveness of some antibiotics because of the use of antibiotic-resistant marker genes (GAO 1993). 
of adverse environmental impacts. Rogoff and Rawlins (1987) add another dimension to this list: that biotechnology will raise yields and standards of living for the world without requiring more natural resources. This increase in food security, they assert, may come from the conversion of biomass that can be grown without high inputs of nonrenewable resources - indeed, maybe even without soils.

\section{THE ANXIETIES OF BIOTECHNOLOGY}

The critics of these arguments rebut them with arguments of their own.

Fewer, Less Harmful Chemicals?

The critics are highly skeptical that biotechnological products will result in the reduced use of harmful chemicals. They point to current biotechnology investments as evidence. Many critics assert that with herbicide-resistant crops, herbicide use will increase (e.g., Busch et al. 1991; Hindmarsh 1991; Russell 1993). They note that herbicide-resistant croplines are mostly the product of transnational corporations that are moving quickly to develop plants resistant to herbicides still under patent. The critics are concerned about the dominance of large transnational firms such as Monsanto, which is engineering into plants a tolerance to glyphosate and marketing the end re-

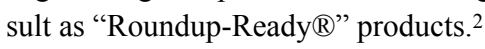

In another example, Calgene, Inc. is petitioning the U.S. Department of Agriculture (USDA) for approval of bromoxynil-tolerant cotton for commercial use; a move the environmental groups fear will lead to increased use of bromoxynil. ${ }^{3}$ Bromoxynil has been implicated with birth defects in laboratory mammals, is considered a developmental toxicant in humans, and is highly toxic to fish and plants (The Gene Exchange 1994). Another example is the development of plants in Australia that are 2,4-D resistant (Hindmarsh 1991).

Critics also fear the transfer of the engineered genes of herbicide-resistant crops to wild relatives or to weeds, or that the transgenic plants themselves will become weeds (Ellstrand 1993; Rissler and Mellon 1993). Hinkle (1992) points out that the reason for the existence of a market for herbicideresistant plants is because weeds have become herbicide resistant over time. If there is a transfer of bioengineered resistance to weeds, weed populations will increase and cause "the pesticide treadmill to accelerate" (Hindmarsh 1991:198).

Tiedje et al. (1989) summarizes the concerns of many ecologists that gene transfer is possible. They note - in boldface type - that:

The available scientific evidence indicates that lateral transfer among microorganisms in nature is neither so rare that we can

\footnotetext{
2 Roundup is Monsanto's trade name for glyphosate which is the world's largest selling herbicide (Busch et al. 1991).

${ }^{3}$ Rissler and Mellon (1991) estimate that if current uses of bromoxynil are maintained, then the adoption of the bromoxynil-resistant cotton with only one-half of the cotton acreage in the U.S. would more than double the use of the chemical.
} 
ignore its occurrence, nor so common that we can assume the barriers crossed by modern biotechnology are comparable to those constantly crossed in nature (p. 304).

Ecologists in particular worry about the release of new products that they view as analogous to the release of "exotics"- animals or plants not native to a region - into an area. While many such releases have proven quite valuable (much of the North American food supply is from exotics); unfortunate outcomes have been all too frequent, causing habitat or crop damage or the extinction of indigenous species. Undesirable exotics, have, for example, included rabbits in Australia, zebra mussels in the Great Lakes, starlings in America, tumbleweeds in western North America. Thus, there is concern that bioengineered products - be they corn and soybeans engineered to withstand a rain forest climate or marine fish engineered to tolerate colder waters - may replace valued native species, such as the tropical forests or cold water fish, or otherwise disrupt existing ecological communities (Drake et al. 1988).

This concern is heightened by the perception that transgenic organisms are things that nature could never create (Witt 1985). Drake and colleagues summarize this concern by noting that "biologists" ability to manipulate an organism's genome has far outstripped knowledge of the ecology of those species" (1988:422). While many of these concerns involve biotechnological manipulations for weed protection, analogous arguments apply to disease or insect pest protection. For example, genetic resistance in insects to pesticides is well documented (Georghiou 1989). As one observer noted, "insects as a group have never met a chemical they couldn't take to the mat" (Hinkle 1992 quoting Fred Gould). One concern, then, is that transgenic biopesticides will exert strong selection pressures in favor of pests with a resistance to the natural biotoxins; thus ultimately accelerating pesticide resistance and encouraging more insecticide use (Hindmarsh 1991). There is an additional concern, propelled by recent research findings at Michigan State University, that peanuts engineered to resist viruses may ultimately produce new, more deadly viruses (Schneider 1994).

\section{Feeding The World Using Less Fertilizer?}

The critics of biotechnology are also skeptical of the claims concerning nitrogen-fixing advances as well as those that suggest biotechnology will solve the world's food problems. Despite some evidence to the contrary (Busch et al. 1991), some critics find little progress to praise in increasing the nitrogen-fixing capacity of plants (Russell 1993). Hindmarsh (1991) believes that the engineering of nitrogen-fixation is lower on the corporate research and development agenda than is herbicide-resistance engineering. Furthermore, even if nitrogen-fixing plants were successfully developed such transgenic properties might infect other species, for example, conferring advantages to weeds. Another expressed concern is that the development of plant varieties that absorb more nitrogen will lead to over-application of fertilizers (Busch et al. 1991). 
There is also considerable skepticism that biotechnology breakthroughs will "feed the world." The accusation is that a substantial effort will be expended on the development of products that can be sold to farmers and others in the industrialized world and that these products will not necessarily, or even usually, translate into improved distribution of world food products (Rissler and Mellon 1993; Russell 1993).

More fundamental, perhaps, is the critic's concern that biotechnological products might undermine the sustainability of other countries' agriculture. First, there is a concern that the First World countries are using genetic material from Third World nations with little or no compensation (King 1993). Second, there is concern that biotechnology might transform where and how crops are grown. For example, inexpensive bioengineered vanilla or cocoa could devastate some Third World economies (King 1993).

In addition, some critics fear that the biotechnology industry will exacerbate the world's loss of genetic material by further narrowing the genetic base of the major crops. There is little faith that seed banks provide enough protection from this narrowing process:

Without wild or local strains the world's food crops may be dangerously vulnerable to devastation. Gene banks around the world are already storing and preserving this genetic wealth, but the banks are vulnerable to inadequate funding and lack of attention (King 1993:27).

Coupled with the fear of the loss of biodiversity is the fear that corporate domination of biotechnological products will intensify the dependence of farmers on purchased inputs (Busch et al. 1991).

Farmers who want to use bromoxynil as a cotton herbicide will have to buy a "package" of bromoxynil and bromoxyniltolerant cotton seeds from Rhone-Poulenc - a major manufacturer of bromoxynil and a leading international seed manufacture. On the other hand, farmers who want to buy open-pollinated seed will find it increasingly hard to do so. Consequently, the current trend of farmers switching to ecological methods of farming, like permaculture, organic and biodynamic farming, could be seriously retarded (Hindmarsh 1991:203).

In addition, the bias of biotechnology toward "products" tends to divert attention from the "systems approach" that is required in a truly sustainable farming system (Mellon 1991). Some assert that biotechnology is just another "technological fix" in a long chain of the same that tries to circumvent problems without "questioning the flawed assumptions which gave rise to the problems in the first place" (Hindmarsh 1991:204). 


\section{PUBLIC POLICIES}

To most critics, the regulatory structure surrounding biotechnology development is far from adequate. Mellon (1991) refers to the system as being in "shambles," and for some products like fish, the regulatory oversight is simply nonexistent. Busch et al. note that "important aspects of biotechnology have been omitted from the current regulatory framework" (1991:231). Most agree that it is at best an inadequate patchwork (Lyman 1993; Marois et al. 1991). For example, the General Accounting Office (1993) concludes that it is time for a thorough review of the regulatory structure. Tiedje and his colleagues conclude that "our past 40 years of experience with chemicals in the environment make it reasonable and indeed desirable that genetically modified organisms be introduced cautiously" (1989:307). They continue:

Consequently, an overall record of little or no hazard stemming from the release of the products of traditional agricultural breeding does not legitimately warrant exemption from oversight for future introductions of transgenic organisms that these traditional techniques could not have produced (p. 306).

The lack of a consistent coordinated regulatory environment is thus of particular concern to those involved that there may be more adverse environmental impacts from biotechnology than the optimists suggest.

\section{CONCLUSIONS}

The arguments with respect to biotechnology and the environment as presented here are reflected throughout the literature in varying degrees of concern and urgency. The critics' arguments also meet with disagreement and rebuttals (see, for example, Hauptli et al. 1985 or Harlander 1991). Nevertheless, these are the issues that are framing the debate.

Like many environmental arguments, much of the debate is not so much about the nature and magnitude of the risk, but rather, who should bear the costs if a course of action proves to be in error. Should biotechnology products be readily approved for use, placing the burden of error on the environment? Or should the products be very cautiously screened, placing the burden of error on the inventors and users of the product?

At times an argument over a single biotechnology product or issue might be a proxy for an entire philosophy about the role of technology in society, the organization and structure of agriculture, and about the relationship of people to nature. That alternative philosophies underlie many of the arguments (Batie 1992) is all the more reason to understand and engage the debate because, in a very real sense, the technology we adopt today determines and defines our future (Wenk 1986). 


\section{REFERENCES}

Batie, S.S. 1992. Biotechnology and Science: The Imperatives of Choice. The James C. Snyder Memorial Lecture, March 11. Purdue University, West Lafayette, IN.

Busch, L., W.B. Lacy, J. Burkhardt and L.R. Lacy. 1991. Plants, Power and Profit: Social, Economic and Ethical Consequences of the New Biotechnologies. Basil Blackwell, Cambridge, MA .

Drake, J.A., D.A. Kenny and T. Voskuil. 1988. Environmental Biotechnology. Bioscience. 38(6) June: 420-422.

Ellstrand, N. 1993. How Ya Gonna Keep Transgenes Down on the Farm? The Amicus Journal. 15(1)Spring: 1-31.

General Accounting Office (GAO). 1993. Food Safety and Quality: Innovative Strategies May be Needed to Regulate New Food Technologies. GAO/ RCED-93-142. Government Printing Office, Washington, D.C.

Georghiou, G.P. 1989. Implications of Potential Resistance to Biopesticides. In D.W. Roberts and R.P. Granados, eds. Biotechnology, Biological Pesticides and Novel Plant-Pest Resistance for Insect Pest Management. (July 1988). Boyce Thompson Institute for Plant Research, Cornell University, Ithaca, NY. pp 18-20.

Harlander, S.K. 1991. Biotechnology_A Means of Improving Our Food Supply. Food Technology. 45(4)April: 84-92 and 95.

Hauptli, H., N. Newell and R. M. Goodman. 1985. Genetically Engineered Plants: Environmental Issues. Biotechnology. 3(May): 437-441.

Hindmarsh, R. 1991. The Flawed "Sustainable" Promise of Genetic Engineering. The Ecologist. 2 1(5)Sept/Oct: 196-205.

Hinkle, M. 1992. Limits of Technology. A Presentation Before the Southern Agribusiness Council, January 23. New Orleans, LA.

King, J.W. 1993. Breeding Uniformity: Will Global Biotechnology Threaten Global Biodiversity? The Amicus Journal. 15(1)Spring: 25-30.

Lyman, F. 1993. The Splice of Life. The Amicus Journal. 15(1 JSpring: 19-20.

Marois, J.J., J.I. Grieshop and L.J. Butler. 1991. Environmental Risks and Benefits of Agricultural Biotechnology. Leaflet Series, Agricultural Biotechnology, Purdue University Agricultural Experiment Station, West Lafayette, IN. pp. 1-7.

Mellon, M. 1991. Biotechnology and the Environmental Vision. InJ. Fessenden MacDonald ed. NABC Report 3, Agricultural Biotechnology at the Crossroads: Biological, Social, and Institutional Concerns. National Agricultural Biotechnology Council, Ithaca, NY. pp 65-70.

Rissler, J. and M. Mellon. 1993. Perils Amidst the Promise: Ecological Risks of Transgenic Crops in a Global Market. Union of Concerned Scientists, Washington, D.C.

Rissler, J. and M. Mellon. 1991. National Wildlife Federation comments to the USDA/APHIS on two applications from Calgene, Inc. to field test cotton plants genetically engineered to tolerate the herbicide bromoxynil 
or resist insects and tolerate bromoxynil. National Biotechnology Policy Center, National Wildlife Federation, Washington D.C.

Rogoff, M.H. and S.L. Rawlins. 1987. Food Security: A Technological Alternative. Bioscience. 37(11) December:800-807.

Russell, D. 1993. Miracle or Myth: Is Biotech the Coming Alternative to

Chemical Agriculture, or a Clone of the Past? The Amicus Journal. 15(1)

Spring:20-24.

Schneider, K. 1994. Go Ahead on Altering Crops Prompts a Go-Slow. The New York Times, May 25.

The Gene Exchange. 1994. Union of Concerned Scientists. 4(3/4).

Tiedje, J.M., R.K. Colwell, Y. L. Grossman, R.E. Hodson, R.E. Lenski, R.N. Mack, and P.J. Regal. 1989. The Planned Introduction of Genetically Engineered Organisms: Ecological Considerations and Recommendations. Ecology. 7(2)April:298-315.

Wenk, E. Jr. 1986. Tradeoffs: Imperatives of Choice in a High-Tech World. Johns Hopkins University Press, Baltimore, MD.

Witt, S.C. 1985. Biotechnology and Genetic Diversity. California Agriculture Lands Project, San Francisco, CA. 